\title{
On the Evolution Mechanism between the Offshore and Onshore RMB Market
}

\author{
Yi-rong Ying ${ }^{1, a *}$, Yuan Fang ${ }^{1, b}$, Ling Yang ${ }^{1, c}$ \\ ${ }^{1}$ College of Economics, Shanghai University, shanghai, 200444, China \\ a3pw@sina.com, bfunyuan1990@163.com, Clily_yang20@126.com
}

\begin{abstract}
Keywords: onshore markets; offshore markets; exchange rate style;
Abstract: Under the background of RMB regionalization, use the differential dynamic theory to set up RMB dynamic model of the circulation mechanism between the offshore market and the onshore market, discussed the formation mechanism and effect of the exchange rate spread between the RMB offshore and onshore markets.
\end{abstract}

\section{Introduction}

The appearance of the RMB off shore market is seemed as the defining event of the process of financial liberalization in China. With more participants joining in the market, the market force will influence the exchange rate. We believe price discovery is the most important function of the offshore market. The offshore market will influence the onshore market rates even though the rates are fixed.

Yin-Wong Cheung (2014) ${ }^{[1]}$ did some research on the interaction between the offshore and onshore RMB rate. Through the standard unit root tests, they found both exchange rate series are I(1) process, the co-integration approach that allows to analysis the long term interaction is adopted to investigate the dynamics.Both the Johansen test and Phillips-Ouliaris test rejected the nocointegration null and suggested the presence of one co-integration vector in the bivariate system of $\mathrm{CNY}$ and $\mathrm{CNH}$ exchange rates. The statistic estimate tells us that the two exchange rates tend to move in tandem on average despite some large deviations. The offshore and onshore exchange rates display different equilibrium correction mechanisms - the former exchange rate is not statistically affected by the error correction term while the latter is statistically affected.

Hui Wang, Hongye Liu (2009) ${ }^{[2]}$ study on the relationship and the transmission of information flow of the base period exchange rate between RMB and the NDF. Through the ARCH model and GARCH model, they think the RMB NDF market have the mean spillover effect on the RMB spot market. So there is a two-way volatility spillover effects between RMB spot exchange rate and NDF. This paper didn't give us detailed analysis to the regression results, although the establishment of ARCH model and GARCH model is reasonable and practical.

Weiwei Niu (2014) ${ }^{[3]}$ thinks that our country should improve the proportion of pure offshore transactions and weaken the impact of pure two-way trade. This paper suggests the full expansion of Hong Kong offshore RMB business by increasing participation of non-residents, and promoting the orderly process of internationalization of RMB. But the rise in participation can't be measured accurately, while the acceptance of non-residents to RMB can only be measured through the number and range of using the RMB.

The premise of this paper is that after develop the offshore market, the economic and trade scale of mainland and Hong Kong is invariant. I think this assumption itself is wrong because the development of the offshore market will strongly promote trade and economic scale extent. This paper is theoretically derived based on the assumption. It is lack of empirical research.

\section{Evolution Model}

Let's consider the links between the offshore market and the onshore market. We built following model based on the principles of the Logistic model. 


$$
\left\{\begin{array}{l}
\frac{d x}{d \mathrm{t}}=R_{o f f} x\left[N_{1}(x, y)-x\right] \\
\frac{d y}{d \mathrm{t}}=R_{\text {in }} \mathrm{y}\left[N_{2}(x, y)-y\right]
\end{array}\right.
$$

Where $R_{\text {off }}$ stands for rate of return that investors invest offshore banks; $R_{\mathrm{in}}$ is rate of return that investors invest onshore banks; $\mathrm{x}$ is offshore bank interest rates; $\mathrm{y}$ is onshore bank interest rates. Let's consider $N_{1}(x, y)$ and $N_{2}(\mathrm{x}, \mathrm{y})$ are both linear functions, that is,

$$
\left\{\begin{array}{l}
\frac{d x}{d t}=\boldsymbol{R}_{o f f} x\left[N_{1}(x, y)-x\right]=\boldsymbol{R}_{o f f} x\left[a_{1}^{x+} b_{1}^{y+} c_{1}-x\right] \\
\frac{d y}{d t}=\boldsymbol{R}_{i n} y\left[N_{2}(x, y)-y\right]=\boldsymbol{R}_{\text {in }} y\left[a_{2} x+b_{2} y+c_{2}-y\right]
\end{array}\right.
$$

where $a_{1}$ is proportion of illegal investors in the offshore market; $a_{2}$ is proportion of legal investors in the offshore market; $b_{1}$ is proportion of illegal investors in the onshore market; $b_{2}$ is proportion of legal investors in the onshore market; $c_{1}$ is the largest offshore market interest rate under no regulatory; $c_{2}$ is the largest onshore market interest rate under no regulatory; and $0<a_{i}, b_{i}, c_{i}<1$.

For simplicity, we denote

$$
\left\{\begin{array}{l}
F_{1}=a_{1} x+b_{1} y+c_{1}-x=\left(a_{1}-1\right) x+b_{1} y+c_{1}=\alpha_{1} x+\beta_{1} y+\gamma_{1} \\
F_{2}=a_{2} x+b_{2} y+c_{2}-y=a_{2} x+\left(b_{2}-1\right) y+c_{2}=\alpha_{2} x+\beta_{2} y+\gamma_{2}
\end{array}\right.
$$

Note that $\alpha_{1}=a_{1}-1<0, \beta_{1}=b_{1}>0, \gamma_{1}=c_{1}>0 ; \alpha_{2}=a_{2}>0, \beta_{2}=b_{2}-1<0, \gamma_{2}=c_{2}>0$

From the system (2), it is easily for us to obtain the equilibrium interest rate in the two markets

$$
\left\{\begin{array}{l}
x^{\theta}=\frac{\gamma_{2} \beta_{1}-\gamma_{1} \beta_{2}}{\alpha_{1} \beta_{2}-\alpha_{2} \beta_{1}}>0 \\
y^{\theta}=\frac{\gamma_{1} \alpha_{2}-\gamma_{2} \alpha_{1}}{\alpha_{1} \beta_{2}-\alpha_{2} \beta_{1}}>0
\end{array}\right.
$$

The equilibrium solution is determined by parameters $\alpha_{1}, \alpha_{2}, \beta_{1}, \beta_{2}, \gamma_{1}, \gamma_{2}$. How will the equilibrium solution change if the parameters change? We have the following results.

Theoreml If, $\alpha_{1}<0, \alpha_{2}>0 ; \beta_{1}>0, \beta_{2}<0$ then

$$
\frac{\partial x^{\theta}}{\partial \gamma_{1}}=\frac{-\beta_{2}}{\left(\alpha_{1} \beta_{2}-\alpha_{2} \beta_{1}\right)^{2}}>0 \quad \frac{\partial y^{\theta}}{\partial \gamma_{1}}=\frac{\alpha_{2}}{\left(\alpha_{1} \beta_{2}-\alpha_{2} \beta_{1}\right)^{2}}>0 \quad \frac{\partial x^{\theta}}{\partial \gamma_{2}}=\frac{\beta_{1}}{\left(\alpha_{1} \beta_{2}-\alpha_{2} \beta_{1}\right)^{2}}>0 \quad \frac{\partial y^{\theta}}{\partial \gamma_{2}}=\frac{-\alpha_{1}}{\left(\alpha_{1} \beta_{2}-\alpha_{2} \beta_{1}\right)^{2}}>0
$$


Theorem2 If $\alpha_{1}<0, \alpha_{2}>0 ; \beta_{1}>0, \beta_{2}<0 ; \beta_{1} \gamma_{2}<\beta_{2} \gamma_{1}$ then

$$
\frac{\partial x^{\theta}}{\partial \alpha_{1}}=\frac{-\beta_{2}\left(\gamma_{2} \beta_{1}-\gamma_{1} \beta_{2}\right)}{\left(\alpha_{1} \beta_{2}-\alpha_{2} \beta_{1}\right)^{2}}<0 \frac{\partial y^{\theta}}{\partial \alpha_{1}}=\frac{\alpha_{2}\left(\gamma_{2} \beta_{1}-\gamma_{1} \beta_{2}\right)}{\left(\alpha_{1} \beta_{2}-\alpha_{2} \beta_{1}\right)^{2}}<0 \frac{\partial x^{\theta}}{\partial \alpha_{2}}=\frac{\beta_{1}\left(\gamma_{2} \beta_{1}-\gamma_{1} \beta_{2}\right)}{\left(\alpha_{1} \beta_{2}-\alpha_{2} \beta_{1}\right)^{2}}<0 \frac{\partial y^{\theta}}{\partial \alpha_{2}}=\frac{\alpha_{1}\left(\gamma_{1} \beta_{2}-\gamma_{2} \beta_{1}\right)}{\left(\alpha_{1} \beta_{2}-\alpha_{2} \beta_{1}\right)^{2}}<0
$$

Theorem3 If $\alpha_{1}<0, \alpha_{2}>0 ; \beta_{1}>0, \beta_{2}<0 ; \alpha_{1} \gamma_{2}>\alpha_{2} \gamma_{1}$ then

$$
\frac{\partial x^{\theta}}{\partial \beta_{1}}=\frac{\beta_{2}\left(\gamma_{2} \alpha_{1}-\gamma_{1} \alpha_{2}\right)}{\left(\alpha_{1} \beta_{2}-\alpha_{2} \beta_{1}\right)^{2}}<0 \frac{\partial y^{\theta}}{\partial \beta_{1}}=\frac{\alpha_{2}\left(\gamma_{1} \alpha_{2}-\gamma_{2} \alpha_{1}\right)}{\left(\alpha_{1} \beta_{2}-\alpha_{2} \beta_{1}\right)^{2}}<0 \frac{\partial x^{\theta}}{\partial \beta_{2}}=\frac{\beta_{1}\left(\gamma_{2} \alpha_{1}-\gamma_{1} \alpha_{2}\right)}{\left(\alpha_{1} \beta_{2}-\alpha_{2} \beta_{1}\right)^{2}}>0 \frac{\partial y^{\theta}}{\partial \beta_{2}}=\frac{\alpha_{2}\left(\gamma_{2} \alpha_{1}-\gamma_{1} \alpha_{2}\right)}{\left(\alpha_{1} \beta_{2}-\alpha_{2} \beta_{1}\right)^{2}}>0
$$

The research above of partial derivatives for each parameter can judge the positive or negative according to the known conditions, to determine the influence of the changes the parameters to the equilibrium solution.

Through the results of the partial derivatives, the following conclusions can be draw:

(i) As either $c_{1}$ (the largest offshore market interest rate under no regulatory) or $c_{2}$ (the largest onshore market interest rate under no regulatory) is increase, it will improve the offshore bank interest rates and the onshore bank interest rates at the same time.

(ii) As $b_{1}$ (proportion of illegal investors in the onshore market) is increase, it will reduce the offshore bank interest rates and the onshore bank interest rates at the same time. In the same way, As $b_{2}$ (proportion of legal investors in the onshore market) is increase, will improve the offshore bank interest rates and the onshore bank interest rates at the same time.

(iii) As a $a_{1}$ (proportion of illegal investors in the offshore market) is increase, it will reduce the offshore bank interest rates and the onshore bank interest rates at the same time; While, as $a_{2}$

(proportion of legal investors in the offshore market), will improve the offshore bank interest rates and the onshore bank interest rates at the same time.

Theorem4 If $\frac{\alpha_{2}}{\alpha_{1}}>\frac{4 \beta_{2}}{\beta_{1}}, \frac{2 \beta_{2}}{\beta_{1}}>\frac{\gamma_{2}}{\gamma_{1}}, \frac{\alpha_{2}}{\alpha_{1}}>\frac{2 \gamma_{2}}{\gamma_{1}}$, and $2 \alpha_{1} R_{o f f}+\alpha_{2} R_{i n}>0,2 \beta_{2} R_{i n}+\beta_{1} R_{o f f}>0$, then system (2) does not exist limit cycle.

Proof: Denote

$$
\left\{\begin{array}{l}
\frac{d x}{d t}=R_{o f f} x\left[N_{1}(x, y)-x\right]=R_{o f f} x\left[\alpha_{1} x+\beta_{1} y+\gamma_{1}\right]=P(x, y) \\
\frac{d y}{d t}=R_{\text {in }} y\left[N_{2}(x, y)-y\right]=\mathrm{R}_{\text {in }} y\left[\alpha_{2} x+\beta_{2} y+\gamma_{2}\right]=Q(x, y)
\end{array}\right.
$$

If the condition of theorem 2 is satisfied, then it is obviously that,

$$
\left(2 \alpha_{1} R_{\text {off }}+\alpha_{2} R_{i n}\right) x+\left(2 \beta_{2} R_{i n}+\beta_{1} R_{o f f}\right) y+\gamma_{1} R_{o f f}+\gamma_{2} R_{\text {in }}>0
$$

It means that $d i v=\frac{\partial P}{\partial x}+\frac{\partial Q}{\partial y}>0$ for all $x>0, \quad y>0$

Due to div $>0$ in the first quadrant, therefore, according to the Dulac theorem, there does not exist limit cycle (periodic solution) in the first quadrant in system (2). 


\section{Conclusions}

In the long run, the establishment of Hong Kong RMB offshore market will have influence on the mainland banking system, monetary policy and the Hong Kong dollar residue. We must have a prudent attitude on this issue. The main risks the mainland market financial facing are as follows: Firstly, the banking system will suffer the impact of the credit scale. Secondly, monetary policy tools of partial failure. Thirdly, RMB will alternative the Hong Kong dollar.

The development of offshore financial market is a double-edged sword, the smooth development can enhance the process of RMB internationalization, promote the reform and perfect in bank financial market, guide the marketization of interest rate and exchange rate regime reform. However, if the path of development we choose is inappropriate, or the supervision is inadequate, it is possible to induced systemic risk in the onshore market through the linkage relationship between the offshore and onshore market, it will destroying the stability of domestic financial system. So establish system of risk prevention has important significance to the development of offshore financial market and the stability of the financial system,

The primary problem that Chinese government faces is to prevent money-laundering behavior. The financial action task force (FATF) has made regulatory standards for money laundering: The anti-money laundering forty Suggestions. These forty suggestions become the foundation of later other states to enact anti-money laundering legal system. Chinese government didn't introduced Anti Money Laundering Law until 2007. So, some of the local financial institutions still haven't realized the importance of anti-money laundering. Besides, the anti-money laundering work needs a lot of professional knowledge but the personnel's professional level is not high. The strict confidentiality system in offshore financial market is the umbrella of money laundering.

Another crucial issue that the Chinese government is facing should be the supervision system. The government is trying to strengthen the international supervision and coordination between these two markets. From 2000, the International Monetary Fund (IMF) regularly assess the world major offshore markets, and has formed a more than 40 offshore financial centers more perfect assessment system. The development of financial market in China can draw lessons from the experience of IMF evaluation system. Then China can base on this frame, to form our own risk assessment system. According to IMF assessment system, focus on the development and changes in other offshore market around the world.

\section{Acknowledgment}

This research was supported by National Natural Science Foundation of China under Grant No. 71171128

\section{References}

[1] Yin-Wong Cheung. The offshore renminbi exchange rate: Microstructure and links to the onshore market [J]. Journal of International Money and Finance, 2014(12):170-189.

[2] Hui Wang , Hongye Liu.Research on the RMB offshore market and the domestic market information transmission---empirical analysis based on the NFD exchange rate and the base period exchange rate[J]. Financial Theory \& Practice, 2009(03).

[3] Weiwei Niu.The inspiration of the Hong Kong offshore RMB market for the euro dollar market [J].Southwest Finance, 2014,(3):23-26 